\title{
Creatine Kinase Determination Based on an Electrochemical Impedance Immunosensor
}

Tao Geng, Zhiyuan Song, Jiangang Zhang and Zesheng $X u^{*}$

The Second Department of Cangzhou Cardiovascular Institute, No.16 West Xinhua Rd, Cangzhou, Hebei, 061000, P.R. China

*E-mail: xuzensheng79@163.com

doi: $10.20964 / 2017.09 .60$

Received: 23 May 2017 / Accepted: 20 July 2017 / Published: 13 August 2017

With biosynthesized gold nanoparticles (Au NPs) as the basis, a new electrochemical impedance immunosensor is proposed in this study to determine the concentration of creatine kinase (CK), a cardiac biomarker. This sensor has an extended detecting range of $10 \mathrm{ng} / \mathrm{mL}$ to $0.5 \mu \mathrm{g} / \mathrm{mL}$. Moreover, it features a notable anti-interference trait making this bio-fabricated immunosensor potentially employable in CK detection.

Keywords: Creatine kinase; Electrochemical impedance immunosensor; Gold nanoparticle; Acute myocardial infarction; Clinical measurement

\section{$\underline{\text { FULL TEXT }}$}

(C) 2017 The Authors. Published by ESG (www.electrochemsci.org). This article is an open access article distributed under the terms and conditions of the Creative Commons Attribution license (http://creativecommons.org/licenses/by/4.0/). 